\title{
Simultaneous Removal of Reactive Dyes and Hexavalent Chromium by a Metal Tolerant Pseudomonas sp. WS-D/183 Harboring Plant Growth Promoting Traits
}

\author{
Sabir Hussain ${ }^{1 \dagger}$, Zahid Maqbool ${ }^{1 \dagger}$, Muhammad Shahid ${ }^{2}$, Tanvir Shahzad ${ }^{1}$, Saima Muzammil ${ }^{3}$, Muhammad Zubair ${ }^{2}$, \\ Muhammad Iqbal $^{1}$, Iftikhar Ahmad ${ }^{4}$, Muhammad Imran ${ }^{5}$, Muhammad Ibrahim ${ }^{1}$ and Faisal Mahmood ${ }^{1 *}$ \\ ${ }^{1}$ Department of Environmental Sciences and Engineering, Government College University, Faisalabad, Pakistan \\ ${ }^{2}$ Department of Bioinformatics and Biotechnology, Government College University, Faisalabad, Pakistan \\ ${ }^{3}$ Department of Microbiology, Government College University, Faisalabad, Pakistan \\ ${ }^{4}$ Department of Environmental Sciences, COMSATS University Islamabad, Vehari Campus, Vehari-61100, Pakistan \\ ${ }^{5}$ Environmental Microbiology, Soil Science Division, Nuclear Institute of Agriculture and Biology (NIAB), Faisalabad, Pakistan \\ "For correspondence: fslagronomy@ hotmail.com \\ ${ }^{\dagger}$ Contributed equally to this work and are co-first authors
}

Received 21 August 2019; Accepted 01 October 2019; Published 16 January 2020

\begin{abstract}
Textile industry is a continuous source of colored wastewater. This wastewater frequently used for irrigation purpose in many underdeveloped countries including Pakistan. In this study, we isolated the bacterial strains capable of decolorizing dyes and promote the plant growth. Hence to decolorize the reactive red 120 (RR120), the strain WS-D/183 was optimized following response surface methodology (RSM) based modeling approach. Moreover, strain WS-D/183 was also assessed for plant growth promoting characteristics. Results revealed that the strain WS-D/183 showed a good potential for decolorization of structurally diverse types of azo dyes on reaction with a mixture of heavy metal ions $\left(\mathrm{Cr}^{6+}, \mathrm{Cd}^{2+}, \mathrm{Zn}^{2+}, \mathrm{Pb}^{2+}\right)$. This strain concurrently removed reactive dyes $\left(100 \mathrm{mg} \mathrm{L}^{-1}\right)$ and reduced $\mathrm{Cr}(\mathrm{VI})$. Results showed that each dye was decolorized up to $90 \%$ except reactive yellow-2 which was decolorized up to $57.4 \%$. Furthermore, the bacterium reduced Cr(VI) by 41 to $95 \%$ along with concurrent decolorization of RR120. This bacterium was also found to carry plant growth promoting traits including inorganic phosphate solubilization $\left(497.6 \pm 14.8 \mu \mathrm{g} \mathrm{mL}^{-1}\right)$ and indole-3-acetic acid production $\left(21.07 \pm 0.9 \mu \mathrm{g} \mathrm{mL}{ }^{-1}\right)$. A phytotoxicity evaluation study indicated that irrigation of mung bean [Vigna radiata (L.) Wilczek] with RR120, Cr(VI) and RR120+Cr(VI) contaminated waters treated with the strain WS-D/183 enhanced germination along with plumule and radical length of seedlings. Results suggested that Pseudomonas sp. WS-D/183 is a valuable addition to the bioresources, which can be used to devise textile wastewater treatment strategies as well as for integrated bioremediation and plant growth promotion in agricultural soils contaminated with textile wastewaters. (C) 2020 Friends Science Publishers
\end{abstract}

Keywords: Textile wastewaters; Azo-dyes decolorization; Cr (VI)-reduction; Multi-metal stress; RSM; PGPB; Phytotoxicity; Mung bean

\section{Introduction}

In textile industry, a major proportion of dyes used for dyeing fabrics are azo-dyes. These dyes are preferred over other classes of synthetic dyes due to their low price, ease of application and availability in a variety of colors (Shah et al. 2014). However, a high fraction of the applied quantity ranging between $15-50 \%$ is wiped out in dyeing and washing processes and forms the colored wastewaters (Pratum et al. 2011). Release of colored wastewaters also causes entry of azo dyes in water and soil resources (Tony et al. 2009). Such dyes disrupt light penetration into water, which effect photosynthetic rate of hydrophytes (Shah et al. 2014). It is reported that azo dyes and their metabolites can cause cancer and add poisonous materials in the environment (Carneiro et al. 2010). In addition, entry of such wastewaters in soil resources results into a disturbance in soil microbial communities, soil processes and crop productivity (Arif et al. 2016; Rehman et al. 2018).

Azo dyes and metal-complexed dyes as well as different metal-based salts are also heavily used as mordant for fixation of dyes in textile industry (Desai et al. 2009). Consequently, some metals including cadmium, zinc, chromium and lead can be found in textile wastewater above permissible limits (Tuzen et al. 2008; Imtiazuddin et al. 2014). Presence of dyes and metal ions are the main reason for toxic effects of textile wastewater. Among heavy metal ions, hexavalent $[\mathrm{Cr}(\mathrm{VI})]$ commonly co-exists with

To cite this paper: Hussain S, Z Maqbool, M Shahid, T Shahzad, S Muzammil, M Zubair, M Iqbal, I Ahmad, M Imran, M Ibrahim, F Mahmood (2020). Simultaneous removal of reactive dyes and hexavalent chromium by a metal tolerant Pseudomonas sp. WS-D/183 harboring plant growth promoting traits. Intl J Agric Biol 23:241-252 
azo dyes in effluents of leather and textile industries (Tuzen et al. 2008). Among 17 chemicals, it poses the greatest risk to humans (Quintelas et al. 2008). Hence, it is important to develop remediation approaches for concurrent elimination of dyes and hexavalent chromium from wastewater of leather and textile industry.

Previous studies showed that biotic methods for removal of organic and inorganic pollutants are one of innovative, economic and environmental viable techniques (Imran et al. 2015a). In this perspective, researchers have identified several bacteria having potential to degrade the textile dyes (Imran et al. 2016; Hussain et al. 2017). Similarly it has been reported that microbes have the potential to detoxify Cr(VI) metal (Park et al. 2006). Furthermore, some efforts of isolating, identifying and characterizing microbes capable of concurrently degrading azo dyes and detoxifying $\mathrm{Cr}(\mathrm{VI})$ have met with success (Hussain et al. 2017). Therefore, there is a need to isolate more efficient bioresources which can remove dyes and reduce $\mathrm{Cr}(\mathrm{VI})$ and exhibit the tolerance against other coexisting metal ions. In this study, we isolated and characterize the metal tolerant bacterium capable of removing dyes and reduce $\mathrm{Cr}(\mathrm{VI})$ in a medium spiked with a mixture of $\mathrm{Pb}^{2+}, \mathrm{Cd}^{2+}$ and $\mathrm{Zn}^{2+}$.

\section{Materials and Methods}

\section{Growth media for bacterial growth}

A mineral salt medium (MSM) spiked with four heavy metals was used to isolate metal-tolerant, dye degrading bacterial isolate. The ingredients of MSM used in this study are given in Maqbool et al. (2016). The mineral salt medium was spiked with four different heavy metal salts as previously reported in Maqbool et al. (2016). However, pH of MSM was maintained at 7.2 using basic and acidic solutions.

\section{Isolation, Screening and molecular identification of isolate WS-D/183}

For bacterial isolation, effluent samples were taken from outlets of various textile industries. These industries were located near Sargodha Road, Faisalabad, Pakistan. Serial dilution of collected wastewater samples was performed and about $100 \mu \mathrm{L}$ of $10^{-3}-10^{-6}$ dilutions was poured on MSM agar plates. These plates were spiked with selected heavy metals and placed in static incubator at $30^{\circ} \mathrm{C}$. The bacterial isolates having variable size, color and shape were purified through streaking thrice using MSM agar plates. To prepare inoculum of each isolate, the cultures of all bacterial isolates were inoculated in Erlenmeyer flasks and incubated at $30^{\circ} \mathrm{C}$ for $72 \mathrm{~h}$. By using sterile MSM, the $\mathrm{OD}_{600}$ of all bacterial culture was adjusted as 0.5 . Then, $18 \mathrm{~mL}$ of MSM containing mixture of heavy metals and RR120 were added separately along $2 \mathrm{~mL}$ of isolates in test tubes and incubated at $30^{\circ} \mathrm{C}$. After two days of incubation, removal of initially added dye was determined (Maqbool et al. 2016). The isolate WS-D/183 was selected for further characterization based on its potential to decolorize the RR120.

A 16S rRNA gene amplification and sequencing was done for molecular identification of the strain WS-D/183 (Maqbool et al. 2016). The similarity of this sequence with already known reference sequences of different bacteria was checked as previously reported by Hussain et al. (2013); whereas, phylogenetic tree was made by NJ plot (Perriere and Gouy 1996).

\section{Metal tolerance of isolate WS-D/183}

The metal tolerance of the bacterium was determined by estimating MIC of selected heavy metals. For this purpose, nutrient agar medium was spiked with cobalt, chromium, zinc, lead, nickel, cadmium salts to develop 0-5000 $\mathrm{mg} \mathrm{L}^{-1}$ of given heavy metals. The strain WS-D/183 was streaked on each plate and preserved for five days to check the growth of WS-D/183. The minimum concentration of a particular metal that inhibited growth of the strain WSD/183 was considered as MIC for the strain WS-D/183.

\section{Optimization of RR120 decolorization by isolate WS- D/183}

Bio-decolorization of structurally diverse azo dyes: The ability of WS-D/183 for decolorizing different reactive dyes and direct dyes [orange direct (OD), Congo red (CRD) and blue direct (BD)] was assessed in MSM spiked with mixture of metal ions. The general characteristics of these dyes are given in Table 1. The experiment was conducted in glass vials. The cells of the strain WS-D/183 were added to MSM and $\mathrm{OD}_{600}$ was adjusted at 0.05. After filter sterilization, each dye was added to maintain $100 \mathrm{mg} / \mathrm{L}$ conc. Triplicates of inoculated vials along with un-inoculated control were kept at $30^{\circ} \mathrm{C}$. After $24,48,72$ and $144 \mathrm{~h}$, decolorization was determined as described above.

Optimization of RR120 decolorization by the strain WSD/183 using RSM: Effect of $\mathrm{pH}$, yeast extract, sodium chloride and metal mixture on removal of RR120 via WSD/183 was assessed following RSM. Each selected variable was studied at five levels as previously explained in Maqbool et al. (2016). Small composite design (SCD) comprising of eight factorial points, eight axial runs and five center points was chosen (Maqbool et al. 2016). Decolorization of RR120 determined after $72 \mathrm{~h}$ was set as the response variable as explained above. A second order polynomial model was selected to be estimated through observed data by SCD, as given below;

$$
E(y \mid x)=\beta_{0}+\sum_{i=1}^{k} \beta_{\mathrm{i}} x_{\mathrm{i}}+\sum_{i=1}^{k} \beta_{\mathrm{ii}} x^{2}{ }_{\mathrm{i}}+\sum_{i=1}^{k-1} \sum_{j>i}^{k} \beta_{i j} x_{\mathrm{i}} x_{j}
$$

Where $E(y \mid x)$ represents expected response given vector $\boldsymbol{x}$ of predictor variables, $\beta_{\text {。 }}$ is a regression constant, $\beta_{i}$ is linear regression coefficient, $\beta_{i i}$ is quadratic regression coefficient and $\beta_{i j}$ is bilinear regression coefficients. 
Table 1: General characteristics of azo dyes

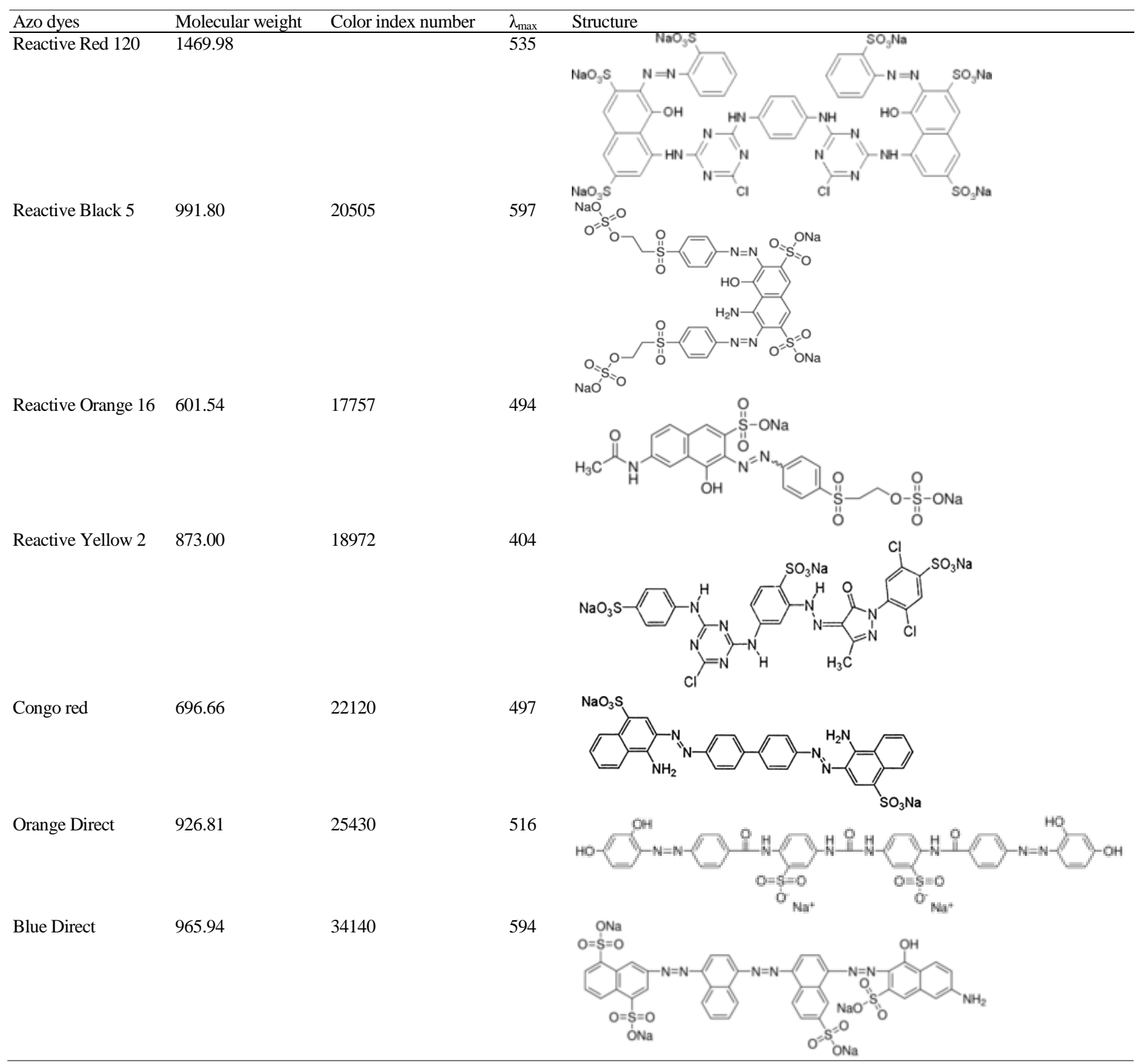

The model adequacy was assessed by lack of fit technique. Lack-of-fit of second-order model indicated that quadratic model lack-of-fit is highly insignificant with low F-value and high p-value. Thus, quadratic polynomial model was more appropriate to describe the relation of response (i.e., decolorization) to the input factors (i.e., $\mathrm{pH}, \mathrm{NaCl}$, yeast extract and heavy metal mixture content). The evaluation of variable significance of whole model was checked by $\mathrm{R}^{2}$ and $F$ test. Moreover, confidence levels were determined to check significance of $R^{2}$. Variance inflation factor was also calculated to measure extent of multicollinearity among two or more input variables of polynomial regression model.

\section{Concurrent removal of RR120 and hexavalent chromium using WS-D/183}

The strain WS-D/183 was also checked for concurrent elimination of RR120 and $\mathrm{Cr}(\mathrm{VI})$ in MSM in the presence of $\mathrm{Zn}^{2+}, \mathrm{Pb}^{2+}$ and $\mathrm{Cd}^{2+}$ mixture. In first step, the bacterium was checked for $\mathrm{Cr}(\mathrm{VI})$ removal in MSM taken in glass vials. The supernatants taken over time were analyzed for $\mathrm{Cr}(\mathrm{VI})$ content with diphenylcarbazide (DPC) method (Anwar et al. 2014). After confirmation of $\mathrm{Cr}(\mathrm{VI})$ reduction, it was evaluated for concurrent elimination of RR120 and hexavalent chromium. For this purpose, filter sterilized RR120 was added to MSM spiked with $\mathrm{Cr}^{+6}, \mathrm{Zn}^{2+}, \mathrm{Pb}^{2+}$ and $\mathrm{Cd}^{2+}$. After inoculation, vials along with 
un-inoculated controls were placed in an incubator. The supernatant was collected after 0, 30, 60, 90, 120, 150, 180 and $210 \mathrm{~h}$. It was used to measure decolorization and removal of $\mathrm{Cr}(\mathrm{VI})$ by using DPC method, whereas, bacterial pellet was used to measure growth of the bacterium. The bacterial pallets were rinsed and suspended in distilled water. $\mathrm{OD}_{600}$ was determined using a CO800 Cell Density Meter (Biochrom, England).

\section{Assessment of PGPR traits of WS-D/183}

We studied the indole acetic acid (IAA) and phosphorus solubilization as indices of PGPR traits. Gordon and Weber (1951) method was employed to determine IAA production by the bacterial strain. Briefly, LB broth containing Ltryptophan, IAA precursor, was inoculated with the strain WS-D/183. After 48, 120 and $240 \mathrm{~h}$ of incubation, IAA content and $\mathrm{pH}$ of the supernatant were determined. For IAA measurement, two drops of $\mathrm{H}_{3} \mathrm{PO}_{3}$ and $1 \mathrm{~mL}$ Salkowski reagent were added to supernatants and kept at room temperature for few minutes. The strength of pink color developed was assessed at $530 \mathrm{~nm}$. A calibration plot was developed using IAA standards and used to determine IAA.

For measuring phosphate solubilization, NBRIP broth medium having tri-calcium phosphate as insoluble phosphorus source was prepared. The broth was inoculated with the culture of the strain WS-D/183 and incubated under static conditions. After 48, 120 and 240 $\mathrm{h}$ of incubation, phosphorus content and $\mathrm{pH}$ of the filtrate were determined. Aliquots taken after regular intervals were filtered using Whattman No. 1 filter paper. Afterwards, the filtrate was subjected to centrifugation to get clear supernatant. The supernatants were used for measuring phosphate solubilization as previously reported by Maqbool et al. (2018).

\section{Phytotoxicity Evaluation of the wastewater treated with WS-D/183}

Three MSM flasks containing $500 \mathrm{mg}$ RR120 L $\mathrm{L}^{-1}, 25 \mathrm{mg}$ $\mathrm{Cr}(\mathrm{VI}) \mathrm{L}^{-1}$ and $\mathrm{RR} 120+\mathrm{Cr}(\mathrm{VI})$ were inoculated with the strain WS-D/183 for $72 \mathrm{~h}$ in order to obtain treated water for phyto-toxicity evaluation of the strain. The untreated RR120, Cr(VI) and RR120+Cr(VI) along with their respective treated counterparts were used to determine their toxicity on seed germination of mung bean [Vigna radiata (L.) Wilczek]. Ten seeds were sown in sand taken in petri plates. The sand plates containing seeds according to the below given eight treatments were watered. Experiment was conducted in triplicate in growth chamber where plants received the light for $16 / 8 \mathrm{~h}$ light/dark periods at temperature of $25 / 30^{\circ} \mathrm{C}$ and day/night humidity of $70 / 90 \%$. After 10 days, germination (\%), radical length and plumule length was measured.

Treatments: $\mathrm{T}_{0}=$ No dye, $\mathrm{T}_{1}=\mathrm{RR} 120 @ 500 \mathrm{mg} \mathrm{L}^{-1}$, $\mathrm{T}_{3}=\mathrm{Cr}(\mathrm{VI}) @ 25 \mathrm{mg} \mathrm{L}^{-1}, \mathrm{~T}_{4}=\mathrm{RR} 120 @ 500 \mathrm{mg} \mathrm{L}^{-1}+$ $\mathrm{Cr}(\mathrm{VI}) @ 25 \mathrm{mg} \mathrm{L}^{-1}, \mathrm{~T}_{5}=\mathrm{No}$ dye $+\mathrm{WS}-\mathrm{D} / 183, \mathrm{~T}_{6}=$
RR120@500 mg L ${ }^{-1}+\mathrm{WS}-\mathrm{D} / 183, \mathrm{~T}_{7}=\mathrm{Cr}(\mathrm{VI}) @ 25$ $\mathrm{mg} \mathrm{L} \mathrm{L}^{-1}+\mathrm{WS}-\mathrm{D} / 183, \mathrm{~T}_{8}=\mathrm{RR} 120 @ 500 \mathrm{mg} \mathrm{L}^{-1}+$ Cr(VI)@25 mg L ${ }^{-1}+$ WS-D/183.

\section{Statistical analysis}

Analysis of the observed experimental data in RSM was carried out using Design Expert 9 software. Fitness of the model used in this study was evaluated using a number of parameters. Moreover, one way analysis of variance (ANOVA) was used for determination of significance of treatment effects on growth of mung bean. Tukey's HSD test was used for multiple means comparisons for parameters where significant treatment effects were found. Tables and figures contain means and standard errors of means from three replicates. All statistical analyses were performed using Statistix8.1 software.

\section{Results}

\section{Molecular identification of the isolate WS-D/183}

More than 200 bacteria were isolated and checked for decolorization of RR120 in MSM spiked with a mixture of $\mathrm{Cr}^{6+}, \mathrm{Pb}^{2+}, \mathrm{Cd}^{2+}$ and $\mathrm{Zn}^{2+}$. The decolorization ranged from $1.3 \pm 1.1$ to $95.6 \pm 3.2 \%$ for various bacterial isolates. The maximum decolorization of the RR120 was shown by the isolate WS-D/183. Bioinformatic analysis of $16 \mathrm{~S}$ rRNA gene of the isolate WS-D/183 through BLASTn revealed that it had the highest similarity with several species of genus Pseudomonas. Moreover, during phylogenetic analysis the isolate WS-D/183 (GeneBank Accession No. MG547881) was clustered with bacterial spp. belonging to genus Pseudomonas (Fig. 1). Moreover, phylogenetic tree revealed that WS-D/183 belongs to genus Pseudomonas and designated as Pseudomonas sp. WS-D/183 (Fig. 1).

\section{MIC of metal ions for Pseudomonas sp. WS-D/183}

The MIC of six metals for growth of Pseudomonas sp. WS$\mathrm{D} / 183$ is presented in Table 2 . The strain WS-D/183 showed variable resistance towards metal ions. The $\mathrm{MIC}$ of $\mathrm{Co}^{2+}$, $\mathrm{Cr}^{6+}, \mathrm{Zn}^{2+}, \mathrm{Pb}^{2+}, \mathrm{Ni}^{2+}$ and $\mathrm{Cd}^{2+}$ for the bacterium were 13.58, $9.62,30.59,4.83,3.41$ and $44.48 \mathrm{~m} M$, respectively.

\section{Potential of WS-D/183 to decolorize structurally diverse textile dyes}

Pseudomonas sp. WS-D/183 showed excellent removal of selected reactive and direct dyes (Table 3). However, it was observed that it showed higher decolorization of reactive than direct dyes. After $24 \mathrm{~h}$ treatment, the strain WS-D/183 showed maximum decolorization of RB5 (53.5 $\pm 1.1 \%)$ followed by RR120 (18.3 $\pm 1.3 \%)$ and RY2 (17.7 $\pm 3.2 \%)$ as compared to $14.7 \%( \pm 1.7), 7.5 \%( \pm 2.7)$ and $3.4 \%$ $( \pm 1.1)$ decolorization of $\mathrm{BD}, \mathrm{CRD}$, OD, respectively. However, after $144 \mathrm{~h}$, more than $96 \%$ of the added RR120 
Bioremediation of Dyes and Cr(VI) in Textile Wastewater / Intl J Agric Biol, Vol 23, No 2, 2020

Table 2: Metal resistance (MIC) of different heavy metals by WS-D/183

\begin{tabular}{lll}
\hline Metals & Source & MIC $(\mathrm{m} M)$ \\
\hline Cobalt & $\mathrm{Co}\left(\mathrm{NO}_{3}\right)_{2}$ & 13.58 \\
Chromium & $\mathrm{K}_{2} \mathrm{Cr}_{2} \mathrm{O}_{7}$ & 9.62 \\
Zinc & $\mathrm{ZnSO}_{4}$ & 30.59 \\
Lead & ${\mathrm{Pb}\left(\mathrm{NO}_{3}\right)_{2}}_{2}$ & 4.83 \\
Nickel & $\mathrm{NiCl}_{2} \cdot 6 \mathrm{H}_{2} \mathrm{O}$ & 3.41 \\
Cadmium & $\mathrm{CdCl}_{2}$ & 44.48 \\
\hline
\end{tabular}

Table 3: Potential of Pseudomonas sp. WS-D/183 for removal of reactive and direct dyes

\begin{tabular}{|c|c|c|c|c|}
\hline Dyes & Color remo & & & \\
\hline & $24 \mathrm{~h}$ & $48 \mathrm{~h}$ & $72 \mathrm{~h}$ & $144 \mathrm{~h}$ \\
\hline Reactive Red 120 (RR120) & $18.3 \pm 1.3$ & $26.3 \pm 0.8$ & $65.0 \pm 2.1$ & $96.1 \pm 2.3$ \\
\hline Reactive Orange 16 (RO16) & $4.9 \pm 2.4$ & $31.4 \pm 1.2$ & $49.9 \pm 2.7$ & $63.7 \pm 2.4$ \\
\hline Reactive Yellow 2 (RY2) & $17.7 \pm 3.2$ & $58.4 \pm 2.1$ & $60.6 \pm 3.4$ & $64.2 \pm 2.1$ \\
\hline Congo Red direct (CRD) & $7.54 \pm 2.7$ & $23.7 \pm 1.4$ & $43.2 \pm 2.1$ & $72.5 \pm 1.5$ \\
\hline Orange Direct (OD) & $3.4 \pm 1.1$ & $11.8 \pm 2.3$ & $26.7 \pm 1.7$ & $34.6 \pm 3.2$ \\
\hline Blue Direct (BD) & $14.7 \pm 1.7$ & $33.8 \pm 2.6$ & $41.5 \pm 1.8$ & $48.2 \pm 2.6$ \\
\hline
\end{tabular}

Values are means of three replicates followed by \pm standard error of means $(n=3)$

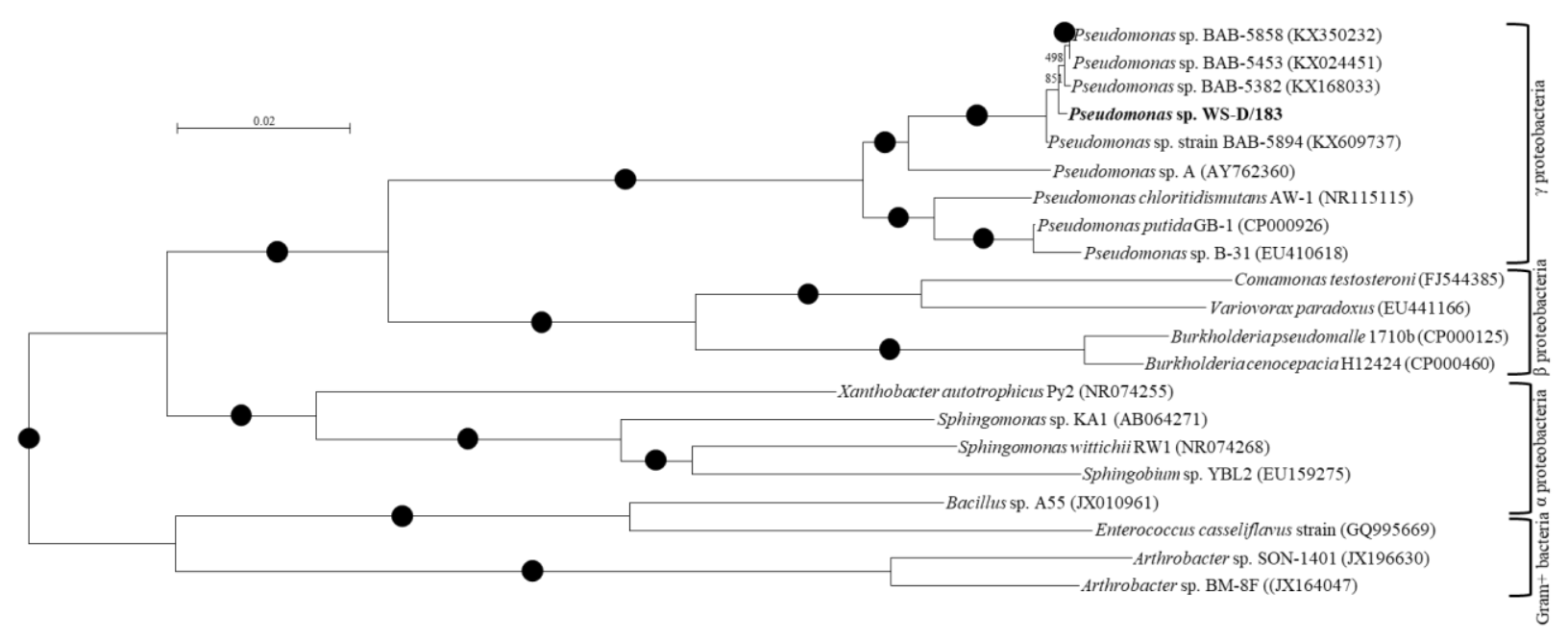

Fig. 1: Phylogenetic tree analysis using multiple alignment of 16S rRNA gene sequence of Pseudomonas sp. WS-D/183

was decolorized followed by RB5 $(89.2 \pm 1.1 \%)$, RY2 $(64.2 \pm 2.1 \%)$ and RO16 (63.7 $\pm 2.4 \%)$. The other dyes CRD, $\mathrm{BD}$ and OD dyes were decolorized up to $72.5( \pm 1.5 \%), 48.2$ $( \pm 2.6 \%)$ and $34.6( \pm 3.2 \%)$ respectively, over the same treatment period.

Optimization of RR120 dye decolorization by Pseudomonas sp. WS-D/183 using RSM

Validation and importance of RSM model: Response surface methodology was used to optimize four different variables for biodecolorization of RR120. The quadratic model showed lowest sequential p-value (0.0001). Data for sequential model selection suggested preferring quadratic over two-factor interaction model because it had very low $p$ value (Table 4). Moreover, cubic model terms were found different from each other. The model validation showed a high value of $R^{2}=0.8531$ with adjusted- $R^{2}=0.6736$. This indicated a big share of variation in response that can be addressed by quadratic polynomial model. Furthermore, "Adeq precision" ratio was found as 9.846. Predicted residual sum of square (PRESS) determines how well the hypothesized model is being estimated by the design. Lower PRESS value showed good performance of the model. Quadratic model showed lower PRESS as compared to other models.

The estimated regression model is presented below which shows the contribution of different second-order model terms for the response.

Decolorization $=21.42-8.63^{x_{1}}+13.06^{x_{2}}+$ $15.96^{x_{3}}-1.55^{x_{4}}+2.21^{x_{1}^{2}}+6.88^{x_{2}^{2}}-8.79^{x_{3}^{2}}-0.24^{x_{4}^{2}}$ $-9.65^{x_{1} x_{2}}-3.21^{x_{1} x_{3}}+7.67^{x_{1} x_{4}}+6.20^{x_{2} x_{3}}-$ $2.03^{x_{2} x_{4}}+10.22^{x_{3} x_{4}}$

Salt $\left(x_{1}\right)$ and metal concentration $\left(x_{4}\right)$ are contributing 
Hussain et al. / Intl J Agric Biol Vol. 23, No. 2, 2020

Table 4: Summary of data statistics regarding model selection

\begin{tabular}{llllll}
\hline Source & Sequential p-value & Lack of Fit p-value & Adjusted R-Squared & Predicted R-Squared & \\
\hline Linear & 0.0463 & 0.0017 & 0.3102 & -0.1671 & -4.5158 \\
2FI & 0.4105 & 0.0013 & 0.3479 & 0.9910 & Suggested \\
Quadratic & 0.0001 & 0.9802 & 0.9793 & & Aliased \\
Cubic & 0.9802 & & 0.9742 & & \\
\hline
\end{tabular}

Table 5: Analysis of variance (ANOVA) for RR120 decolorization using quadratic model

\begin{tabular}{|c|c|c|c|c|c|c|}
\hline Source & Sum of Squares & $\mathrm{df}$ & Square & F Value & p-value Prob > F & \\
\hline Model & 7802.11 & 14 & 557.29 & 65.30 & 0.0001 & significant \\
\hline A-Salt & 596.51 & 1 & 596.51 & 69.90 & 0.0004 & \\
\hline B-pH & 1364.51 & 1 & 1364.51 & 159.89 & $<0.0001$ & \\
\hline C-C-Source & 2265.36 & 1 & 2265.36 & 265.45 & $<0.0001$ & \\
\hline D-Metal Conc. & 19.10 & 1 & 19.10 & 2.24 & 0.1949 & \\
\hline $\mathrm{AB}$ & 372.20 & 1 & 372.20 & 43.61 & 0.0012 & \\
\hline $\mathrm{AC}$ & 82.37 & 1 & 82.37 & 9.65 & 0.0266 & \\
\hline $\mathrm{AD}$ & 235.24 & 1 & 235.24 & 27.57 & 0.0033 & \\
\hline $\mathrm{BC}$ & 307.64 & 1 & 307.64 & 36.05 & 0.0018 & \\
\hline $\mathrm{BD}$ & 16.42 & 1 & 16.42 & 1.92 & 0.2240 & \\
\hline $\mathrm{CD}$ & 834.97 & 1 & 834.97 & 97.84 & 0.0002 & \\
\hline$A^{2}$ & 120.69 & 1 & 120.69 & 14.14 & 0.0131 & \\
\hline $\mathrm{B}^{2}$ & 1164.92 & 1 & 1164.92 & 136.50 & $<0.0001$ & \\
\hline$C^{2}$ & 989.08 & 1 & 989.08 & 115.90 & 0.0001 & \\
\hline $\mathrm{D}^{2}$ & 1.37 & 1 & 1.37 & 0.16 & 0.7055 & \\
\hline Residual & 42.67 & 5 & 8.53 & & & \\
\hline Lack of Fit & 0.007411 & 1 & 0.007411 & 0.00069 & 0.9802 & not significant \\
\hline Pure Error & 42.66 & 4 & 10.67 & & & \\
\hline Corrected Total & 7844.78 & 19 & & & & \\
\hline
\end{tabular}

negatively to remove RR120 dye by WS-D/183, though the contribution of metal concentration is comparatively very low. The $\mathrm{pH}\left(x_{2}\right)$ and Yeast extract $\left(x_{3}\right)$ are positively contributing for the response, so their quadratic effects and the interaction are also high. It is interesting to note that metal concentration has low linear as well as quadratic effects but this is strongly positively contributing for response when interacts with salt and Yeast extract. Salt and $\mathrm{pH}$ also have strong but negative contribution for biodecolorization of RR120 azo dye.

The ANOVA is presented in Table 5. Highly significant model with a low p-value again qualifies the second-order model. The significance of $\mathrm{R}^{2}$ was calculated by estimating confidence limits; all $\mathrm{R}^{2}$ were found in range of confidence limits. High $\mathrm{R}^{2}=0.8531$ and adjusted $\mathrm{R}^{2}=0.6736$ confirmed the model reliability.

Fig. 2 shows 3D plots for graphic appreciation of analysis. Fig. $2(\mathrm{a}-\mathrm{c})$ show normal probability plot constructed for externally studentized residuals and normal $\%$ age probabilities, a plot constructed for predicted versus externally studentized residuals and a plot for run number (design point) against externally studentized residuals, respectively. These are diagnostic plots used to assess the leverage of each design point. We can observe that one design point is exerting undue leverage for the response which may be regarded as an outlier. The analysis of data in the presence of an outlier may be misleading. Therefore, for the further analysis we ignore that outlier. From Fi. 2(d) we can see that actual data is lying along predicted line, which means that it is a good fit of quadratic model. Fig. 2(e) presents Box-Cox plot drawn for lambda (power variable) vs the natural $\log$ of sum of squares of residuals. The lambda value corresponding to the lowest residual value is the natural choice. The perturbation plot depicted the impact of an input variable on the response when it is varied from a reference point, which is usually the central level. Clearly, the response is highly insensitive to varying levels of metal concentration. Cook's distances are plotted in Fig. 2(g) showing the random effect changes if a point is deleted. All cook's distances lie within the acceptable range. Fig. 2(h) shows the plot of leverage values against runs. All leverage values lie in the interval of 0 and 1 . Difference in fits (DFFITS) measures the amount of influence the ith observation has on the predicted response. All DFFITS values lie in the acceptable interval $(-2,2)$ (Fig. 2(i)). Another measure which is closely related to DFFITS is known as DFBETAS, which measures changes in the model related to each regression coefficient (Fig. 2j). Most values lie along the straight line representing 0 .

\section{Separate and interactive effects of input variables on output variable}

Individual, quadratic and interactive effects of selected four parameters on RR120 decolorization by WS-D/183 are shown in Table 5. Effect of salt concentration, $\mathrm{pH}$ and yeast extract content was significant but metal mixture concentration did not show a significant linear contribution in RR120 decolorization. Similarly, quadratic effects of salt concentration, $\mathrm{pH}$ and yeast extract content are also significant $(p<0.05)$ but the quadratic effect of metal mixture concentration is not significant $(p>0.05)$. The salt 

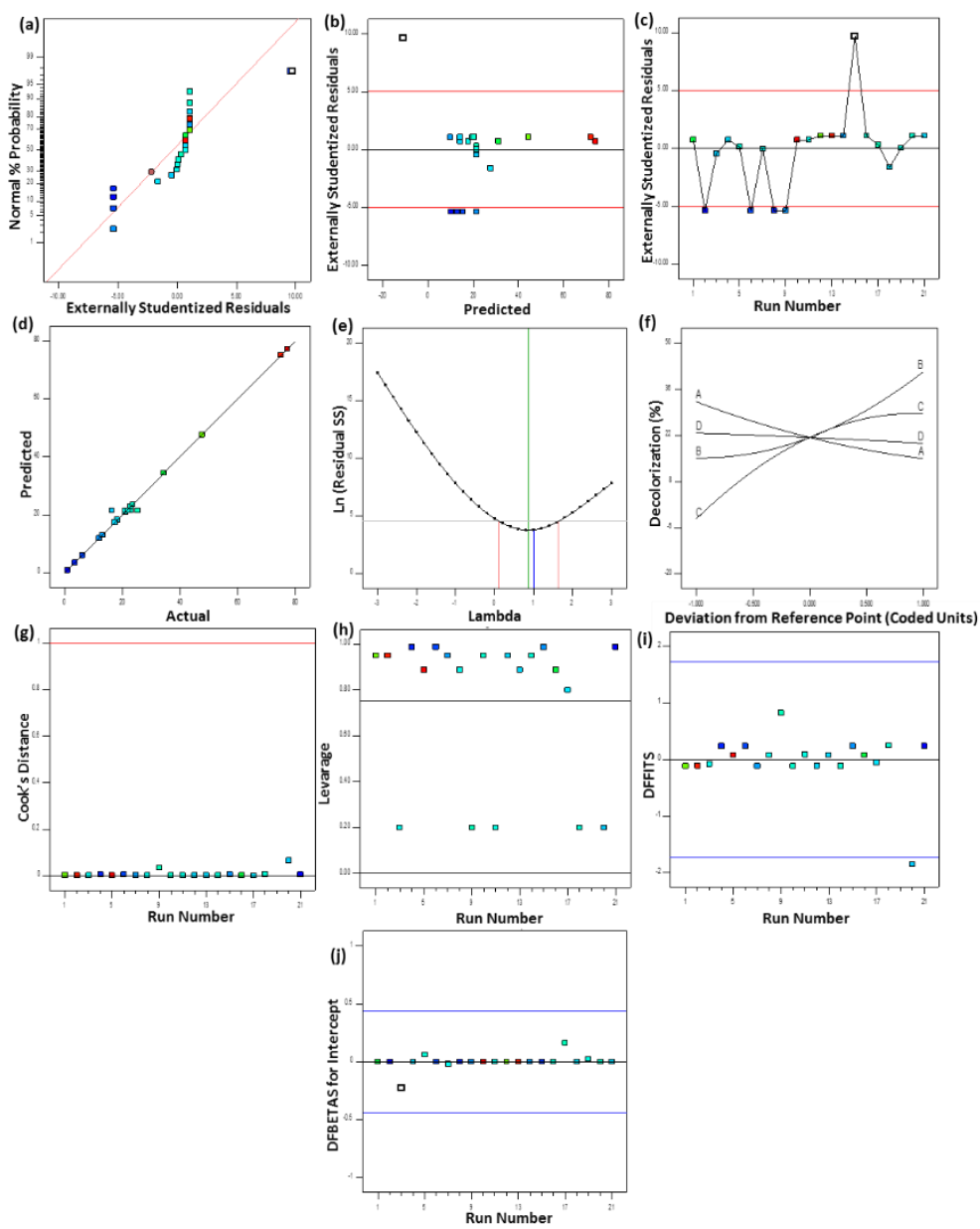

Fig. 2: Diagnostic plots for model validation

concentration and $\mathrm{pH}$, salt concentration and metal mixture concentration, salt concentration and Yeast extract content, $\mathrm{pH}$ and Yeast extract content, and Yeast extract content and metal mixture concentration showed significant $(p<0.05)$ interactive effects on RR120 decolorization by WS-D/183.

A 3-D response plots showed interactive effects of four input variables including $\mathrm{pH}, \mathrm{NaCl}$, yeast extract and metal mixture content on decolorization of RR120 by strain WS-D/183 (Fig. 3). The selected salt concentrations did not significantly affect decolorization of RR120 at low pH (Fig. 3a). However, at higher $\mathrm{pH}$, increasing the salt concentration significantly $(p<0.05)$ decreased RR120 decolorization. Results also indicated that increased concentration of yeast extract resulted in an increase in RR120 decolorization in the presence of lower as well as higher salt concentration levels (Fig. 3b). However, the effect of yeast extract concentration was more pronounced at lower salt concentration. Fig. 3(c) shows the interactive effect of salt and multi-metal mixture concentration on decolorization of RR120 and explains that RR120 decolorization was comparatively less sensitive to changing levels of salt and metal concentration. The interactive effect of $\mathrm{pH}$ and yeast extract content significantly increased the decolorization with increasing values of both variables with the maximum decolorization achieved at highest values of both of these variables (Fig. 3d). Fig. 3(e) shows that decolorization is insensitive to changing levels of multi-metal concentration in contrast to $\mathrm{pH}$ levels which increases decolorization as its level increases. It was also observed that higher concentration of yeast extract was found to have a positive impact on RR120 decolorization in the presence of lower as well as higher concentrations of the multi-metal mixture while keeping the $\mathrm{pH}$ and salt concentration at their middle level (Fig. 3f). Moreover, it was interesting to notice that higher content of multi-metal mixture was found to decrease decolorization of RR120 at lower concentration of yeast extract. According to the model, the optimized values of $\mathrm{pH}$, salt, yeast extract concentration and multi-metal mixture content to achieve the highest were predicted to be $8.0,12.5$ $\mathrm{g} \mathrm{L}^{-1}$ and $7.5 \mathrm{~g} \mathrm{~L}^{-1}$ and a multi-metal mixture $(\mathrm{Cr}: 20$; $\mathrm{Pb}$ : 40; Cd: 20 and $\mathrm{Zn}: 40 \mathrm{mg} \mathrm{L}^{-1}$ ) respectively.

\section{Simultaneous removal of reactive dyes and $\mathrm{Cr}(\mathrm{VI})$ using WS-D/183}

The bacterium did simultaneous removal of all four reactive 

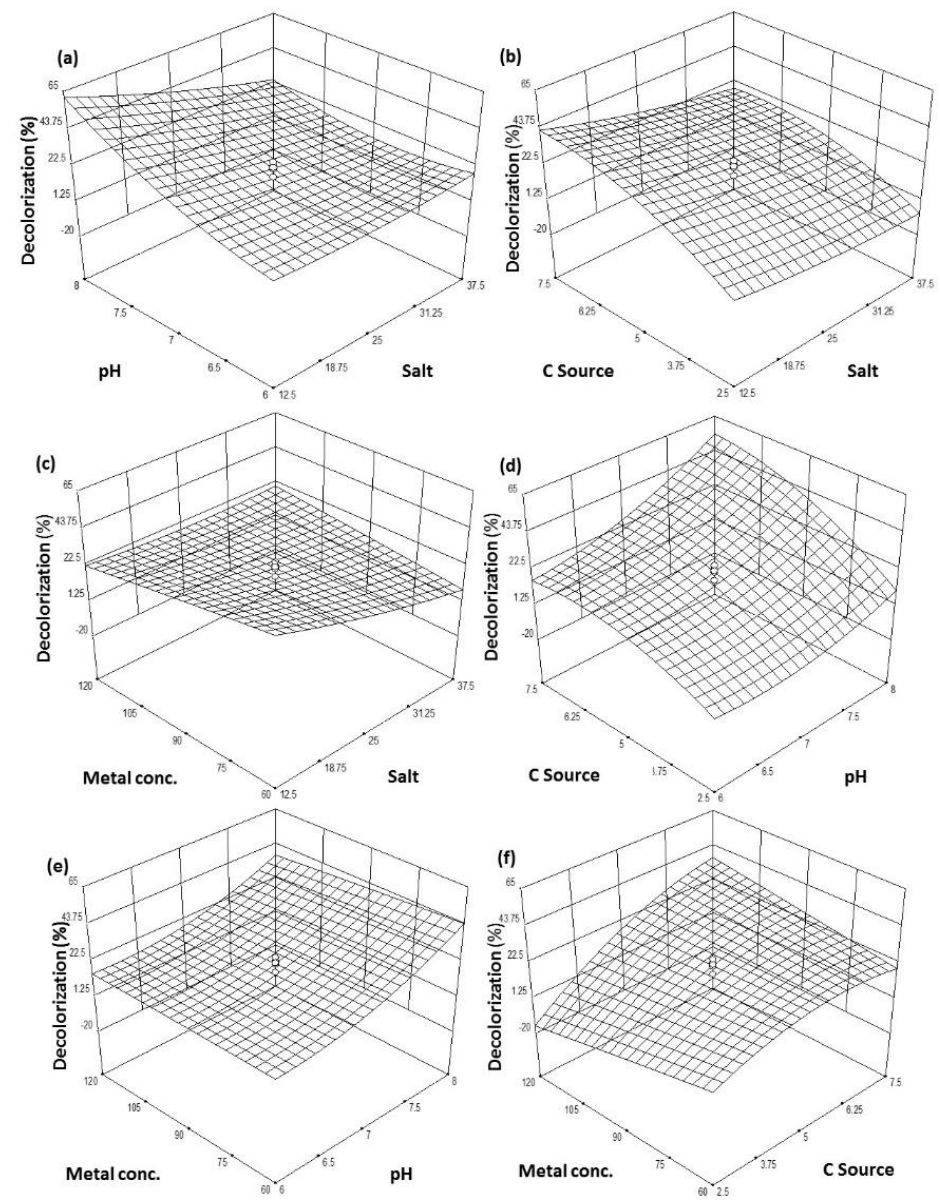

Fig. 3: 3-D Response plots for different factors exhibiting interactive effects of independent variables on decolorization (\%) of RR120 by Pseudomonas sp. WS-D/183

dyes and $\mathrm{Cr}(\mathrm{VI})$ in a medium spiked with $\mathrm{Zn}^{+2}, \mathrm{Cd}^{+2}$ and $\mathrm{Pb}^{+2}$ mixture $(4 \mathrm{a}-4 \mathrm{~d})$. It was observed that during the first $60 \mathrm{~h}$, rate of $\mathrm{Cr}(\mathrm{VI})$ reduction by the strain WS-D/183 was faster than decolorization of reactive dyes. About $62.1 \%$ $( \pm 2.1), 79.8 \%( \pm 1.7), 26.2 \%( \pm 1.1)$ and $43.5 \%( \pm 2.5)$ of 25 $\mathrm{mg} \operatorname{Cr}(\mathrm{VI}) \mathrm{L}^{-1}$ was removed within the first $60 \mathrm{~h}$ in the presence of RR120, RY2, RO16 and RB5, respectively. In parallel to $\mathrm{Cr}(\mathrm{VI})$ removal, RR120, RY2, RO16 and RB5 were decolorized up to $21.4 \%( \pm 0.9), 1.5 \%( \pm 0.6), 2.2 \%$ $( \pm 1.1)$ and $4.6 \%( \pm 1.3)$, respectively during the same incubation period. However, at the end of experiment, decolorization of different dyes reached up to $58-90 \%$, whereas $\mathrm{Cr}(\mathrm{VI})$ removed up to $42-95 \%$. Also, the growth of strain WS-D/183 was monitored and found to be increased during simultaneous removal of textile dyes and $\mathrm{Cr}(\mathrm{VI})$ (Fig. $4 \mathrm{e})$. Furthermore, the $\mathrm{Cr}(\mathrm{VI})$ removal and bacterium growth were significantly correlated to each other (Fig. 4f).

\section{Plant growth promoting traits of the strain WS-D/183}

Table 6 shows that the strain WS-D/183 has considerable potential of IAA production in LB broth amended with tryptophan. IAA content measured after $48 \mathrm{~h}$ was relatively low $(2.23 \pm 0.2)$, however it increased by 8.46 fold after 240 h. Moreover, a gradual decrease in $\mathrm{pH}$ of medium (6.9-5.3) was also recorded during incubation period $(0-240 \mathrm{~h})$.

Clear halo-zones were found around the culture of strain WS-D/183 grown on Pikovskaya's agar plates due to solubilization of TCP in NBRIP medium (data not shown). Based on qualitative analysis, the strain WS-D/183 was inoculated in liquid medium containing tri-calcium phosphate $\left(1000 \mu \mathrm{g} \mathrm{mL}^{-1}\right)$. Results revealed that the strain WS-D/183 showed good potential for phosphate solubilization (Table 6). It was observed that $222 \mu \mathrm{g} \mathrm{mL}^{-1}$ $( \pm 8.5)$ soluble phosphate was released within $48 \mathrm{~h}$ of incubation under shaking conditions. However, at the end of the experiment $(240 \mathrm{~h}), 497.6 \mu \mathrm{g} \mathrm{mL}^{-1}( \pm 14.8)$ soluble phosphate was released by the strain WS-D/183 in the liquid medium under shaking condition at $30^{\circ} \mathrm{C}$. Moreover, gradual decrease in $\mathrm{pH}$ (6.2 to 4.2) of the growth medium was also recorded (Table 6).

\section{Phytotoxicity evaluation}

Data regarding the impacts of untreated and treated wastewater containing RR120 azo-dye as well as $\mathrm{Cr}(\mathrm{VI})$ 
Bioremediation of Dyes and Cr(VI) in Textile Wastewater / Intl J Agric Biol, Vol 23, No 2, 2020

Table 6: Potential of Pseudomonas sp. WS-D/183 for IAA production, Phosphate solubilization and change in pH of media

\begin{tabular}{lllll}
\hline Time & Indole acetic acid production $\left(\mu \mathrm{g} \mathrm{mL}^{-1}\right)$ & $\mathrm{pH}$ & Phosphate solubilization $\left(\mu \mathrm{g} \mathrm{mL}^{-1}\right)$ & $\mathrm{pH}$ \\
\hline 48 & $2.23 \pm 0.2$ & $6.9 \pm 0.2$ & $222.0 \pm 8.5$ & $6.2 \pm 0.3$ \\
120 & $6.16 \pm 0.4$ & $5.9 \pm 0.3$ & $442.1 \pm 9.0$ & $5.1 \pm 0.3$ \\
240 & $21.07 \pm 0.9$ & $5.3 \pm 0.1$ & $497.6 \pm 14.8$ & $4.2 \pm 0.2$ \\
\hline \multicolumn{2}{l}{ Values are means of three replicates followed by \pm standard error of means $(\mathrm{n}=3) \mathrm{p}<0.05$} &
\end{tabular}

Table 7: Evaluation of phytotoxicity of the treated and untreated reactive red-120 (RR120) and hexavalent chromium [Cr(VI)] on Mungbean germination

\begin{tabular}{lllll}
\hline Treatments & Removal $(\%)$ & Germination $(\%)$ & Plumule length $(\mathrm{cm})$ & Radical length $(\mathrm{cm})$ \\
\hline No dye & --- & $83.3 \pm 5.8 \mathrm{a}$ & $9.8 \pm 0.4 \mathrm{a}$ & $5.63 \pm 0.49 \mathrm{abc}$ \\
RR120* & --- & $60.0 \pm 5.0 \mathrm{~cd}$ & $5.3 \pm 0.7 \mathrm{de}$ & $3.53 \pm 0.40 \mathrm{~d}$ \\
Cr(VI)** & --- & $53.3 \pm 2.9 \mathrm{~d}$ & $5.6 \pm 0.8 \mathrm{~d}$ & $3.30 \pm 0.53 \mathrm{~d}$ \\
RR120* + Cr(VI)** & --- & $36.7 \pm 2.9 \mathrm{e}$ & $4.4 \pm 0.6 \mathrm{e}$ & $2.80 \pm 0.66 \mathrm{~d}$ \\
No dye + WS-D/183 & -- & $86.7 \pm 7.6 \mathrm{a}$ & $9.6 \pm 0.9 \mathrm{ab}$ & $5.97 \pm 0.40 \mathrm{a}$ \\
RR120* + WS-D/183 & $92.1 \pm 2.5$ & $71.7 \pm 5.8 \mathrm{~b}$ & $10.3 \pm 0.5 \mathrm{a}$ & $5.83 \pm 0.90 \mathrm{ab}$ \\
Cr(VI)** WS-D/183 & $81.4 \pm 3.1$ & $70.0 \pm 5.0 \mathrm{~b}$ & $8.6 \pm 0.7 \mathrm{bc}$ & $5.97 \pm 0.32 \mathrm{c}$ \\
RR120* + Cr(VI)** WS-D/183 & $>80$ & $68.3 \pm 10.4 \mathrm{bc}$ & $8.4 \pm 1.1 \mathrm{c}$ & $0.38 \mathrm{bc}$ \\
LSD & & 8.6 & 1.04 & 0.77 \\
\hline
\end{tabular}

* RR120 added @ $500 \mathrm{mg} \mathrm{L}^{-1}$, ** Cr(VI) added @ $25 \mathrm{mg} \mathrm{L}^{-1}$

Values are means of three replicates followed by \pm standard error of means $(n=3)$. The means sharing different letters in a column differ significantly at $\mathrm{p}<0.05$ from each other
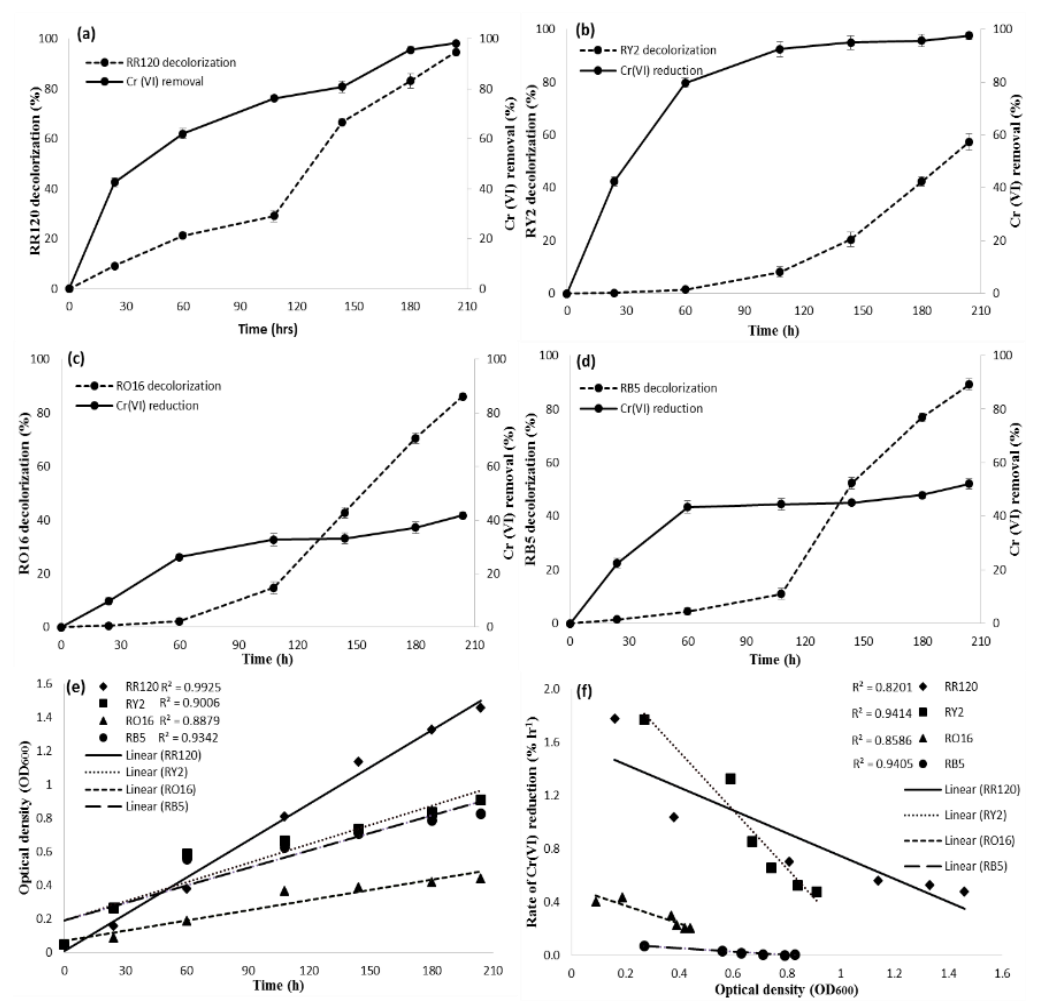

Fig. 4: Simultaneous removal of $\mathrm{Cr}(\mathrm{VI})$ and reactive dyes by Pseudomonas sp. WS-D/183 in MS broth medium containing three other heavy metals $(\mathrm{Zn}, \mathrm{Cd}, \mathrm{Pb})$. (a) Simultaneous removal of $\mathrm{Cr}(\mathrm{VI})$ and reactive red-120. (b) Simultaneous removal of $\mathrm{Cr}(\mathrm{VI})$ and reactive yellow-2. (c) Simultaneous removal of $\mathrm{Cr}(\mathrm{VI})$ and reactive orange-16. (d) Simultaneous removal of $\mathrm{Cr}(\mathrm{VI})$ and reactive black-5. (e) Correlation between growth and time of incubation for removal of $\mathrm{Cr}(\mathrm{VI})$ and reactive dyes by the strain Pseudomonas sp. WS-D/183. (f) Correlation between growth and rate of $\mathrm{Cr}(\mathrm{VI})$ reduction by the strain Pseudomonas sp. WS-D/183

residues on germination, radical length and plumule length of mung bean showed that about $60.0 \%$ ( \pm 5.0$), 53.3 \%$ $( \pm 2.9)$ and $36.7 \%( \pm 2.9)$ seeds of mung bean germinated when they were irrigated with untreated RR120 solution, Cr(VI) solution and RR120+Cr(VI) solution, respectively (Table 7). However, germination of mung bean seeds increased significantly when they were irrigated with treated RR120 solution, $\mathrm{Cr}(\mathrm{VI})$ solution and RR120+Cr(VI) solutions with $71.7 \%( \pm 5.8), 70.0 \%( \pm 5.0)$ and $68.3 \%( \pm$ 10.6) germination, respectively. Similarly, the plumule length was significantly reduced when mung bean was irrigated with RR120 solution $(5.3 \pm 0.7 \mathrm{~cm}), \mathrm{Cr}(\mathrm{VI})$ solution 
$(5.6 \pm 0.8 \mathrm{~cm})$ and RR120+Cr(VI) solution $(4.4 \pm 0.6 \mathrm{~cm})$ as compared to that of water $(9.8 \pm 0.4 \mathrm{~cm})$. However, plumule length of mung bean significantly increased when irrigated with treated RR120 solution, $\mathrm{Cr}(\mathrm{VI})$ solution and RR120+Cr(VI) solution as compared to their respective untreated solutions (Table 7). Similarly application of untreated RR120 solution, $\mathrm{Cr}(\mathrm{VI})$ solution and RR120+Cr(VI) solution significantly decreased radical length. However, application of these solutions after bacterial treatment significantly increased radical length compared to respective untreated solutions (Table 7).

\section{Discussion}

Among more than 200 bacterial isolates tested in this study, the isolate WS-D/183 showed maximum decolorization of RR120. Based on analyses of its $16 \mathrm{~S}$ rRNA gene, the isolate designated as Pseudomonas sp. WS-D/183 (Fig. 1). Previous studies showed that a few bacterial strains of genus Pseudomonas can degrade azodyes (Hussain et al. 2013; Maqbool et al. 2016). It was observed that isolate WS-D/183 has this ability even in the presence of multiple heavy metals ion, which is more commonly encountered in real world.

The strain WS-D/183 showed variable capacity to decolorize the reactive and direct dyes. This might be due to their structure or the varying extent of adaptation of the bacterium to dye environment or differences in electron affinity (Chen et al. 2011; Imran et al. 2015a). Varying decolorization of structurally different dyes have been reported (Imran et al. 2014; Najme et al. 2015; Abbas et al. 2016). Moreover, higher and quicker decolorization of reactive dyes compared to direct dyes suggested that the strain WS-D/183 is more specialized in degrading reactive dyes (Imran et al. 2015a).

The individual and interactive effect of different factors on RR120 decolorization by the strain WS-D/183 was examined following RSM based modelling. RSM has already been employed as a tool for optimizing different cultural and incubation conditions for decolorization purpose (Anwar et al. 2014; Maqbool et al. 2016). The results showed that strain WS-D/183 modified the decolorization rate for RR120. However, no significant effect of multi-metal concentration was observed on bacterial decolorization of RR120 (Fig. 3c-f). It was interesting to note that the individual and quadratic effect of concentration of multi-metal mixture was not significant. However, the interactive effects of metal concentration with yeast extract and salt showed significant decolorization of RR120 (Fig. 3c and d). Such contrasting effects of the concentration on RR120 decolorization can be related to variation in electron withdrawing capacity of metals under variable $\mathrm{pH}$ values (Maqbool et al. 2016). The optimum value of $\mathrm{pH}$ given by RSM was recorded 8.0 for decolorization of RR120. According to previous reports, neutral to slightly alkaline $\mathrm{pH}$ is favorable to decolorize the azo dyes (Imran et al. 2014; Najme et al. 2015). The reason behind this fact might be the negative effects of acidic or highly alkaline $\mathrm{pH}$ on growth of bacterium and activities of dye degrading enzymes (Johansson et al. 2011).

Results also revealed that higher contents of salt had negative effect on decolorization of RR120 by the bacterium. The optimum value of $\mathrm{NaCl}$ contents given by the model was recorded as $12.5 \mathrm{~g} \mathrm{~L}^{-1}$ (Fig. 3). It has been reported that loss of cell integrity, plasmolysis of microbial cells or damage to the enzymatic system of microbial strains involved in decolorization might be the possible reasons for lower decolorization at higher salt contents (Moutaouakkil et al. 2003; Gopinath et al. 2011). It was also found that increasing the concentration of yeast extract substantially accelerated the decolorization of RR120, and $7.5 \mathrm{~g} \mathrm{~L}^{-1}$ of yeast extract was found optimum. This impact of yeast extract might be attributed to three different roles reportedly performed by yeast extract during the decolorization of dyes. It serves not only as a bacterial growth stimulator by providing carbon and nitrogen but also a source of redox equivalents and a redox mediator (Ong et al. 2012; Imran et al. 2016). It must be noted that the effect of all the parameters on RR120 was optimized in the presence of multi-metal mixture which corresponds with the situation prevailing in raw textile wastewaters.

The strain WS-D/183 was found highly potent for concurrent removal of reactive dyes and $\mathrm{Cr}(\mathrm{VI})$ from simulated wastewater in $\mathrm{Cd}^{2+}, \mathrm{Pb}^{2+}$ and $\mathrm{Zn}^{2+}$ mixture. Recently researchers are focusing on isolation, identification and characterization of bacteria able to degraded dyes and tolerate salts and heavy metals (Anwar et al. 2014; Imran et al. 2015b). However, few bacteria are reported which are capable of concurrently degrading dyes and reducing $\mathrm{Cr}(\mathrm{VI})$ (Anwar et al. 2014; Maqbool et al. 2016). This study exhibited slow removal of reactive dyes at the start of incubation by WS-D/183. This inhibition at initial stages can be related to the toxic effects of $\mathrm{Cr}(\mathrm{VI})$ to the bacterium and preferably reduction of $\mathrm{Cr}(\mathrm{VI})$ instead of reactive dyes (Mahmood et al. 2013). Though, higher rate of dye removal seen at final stages could be due to either the decrease in toxicity of $\mathrm{Cr}(\mathrm{VI})$ or acclimatization of the strain WS-D/183 to $\mathrm{Cr}(\mathrm{VI})$ and dyes (Maqbool et al. 2016). Moreover, it is observed that various azo-dyes were removed at variable proportions (Table 3) which suggest the possible variation and electron affinity and dye structure. Previously, Anwar et al. (2014) observed > $80 \%$ removal of $\mathrm{Cr}(\mathrm{VI})$ with substantial removal of dyes. But, this study is unique, as concurrent decolorization of dyes and $\mathrm{Cr}(\mathrm{VI})$ was studied in the occurrence of $\mathrm{Cd}^{2+}, \mathrm{Pb}^{2+}$ and $\mathrm{Zn}^{2+}$ mixture. $\mathrm{Cr}(\mathrm{VI})$ decrease in medium could be due to its biotransformation to Cr(III) by accepting electrons (Wani et al. 2007; Maqbool et al. 2015) or biosorption of $\mathrm{Cr}(\mathrm{VI})$ on the cell surfaces of bacterial strain (Oyetibu et al. 2013).

The strain WS-D/183 showed high potential of IAA production and exhibited a time dependent increase in IAA 
production. Similarly, it was capable of tri-calcium phosphate solubilization. These results suggest that this strain is capable of promoting plant growth in the presence of multi-metal mixture $\left(\mathrm{Cd}^{2+}, \mathrm{Pb}^{2+} \mathrm{Zn}^{+2,} \mathrm{Cr}^{+6}\right)$ and dyes (Table 6). Moreover, $\mathrm{pH}$ of the medium decreased during IAA production and $\mathrm{P}$ solubilization. It might be attributed to the production of low-molecular-weight organic acids (Maliha et al. 2004; Ahemad and Khan 2010; Dwivedi et al. 2011). Literature showed a number of bacterial strains being used for IAA production and $\mathrm{P}$ solubilization (Baig et al. 2014; Shahid et al. 2015; Akram et al. 2016). Researchers also found several bacterial strains having potential to remove dyes and reduce $\mathrm{Cr}(\mathrm{VI})$ under metal stress are very few. Recently, Mahmood et al. (2017) reported a Bacillus sp. carrying PGPR traits and dye decolorization potential.

The RR120 and/or Cr (VI) contaminated water after treatment by the bacterium was tested for toxicity evaluation for plants. Mung bean seeds grown with bacterium treated wastewater showed increased germination, plumule and radical length of mung bean in comparison to seeds grown with untreated wastewater (Table 7). This reduction in phytotoxicity was also supported by the fact that, after inoculation and incubation with strain WS$\mathrm{D} / 183,>80 \%$ of the initially added RR 120 and/or $\mathrm{Cr}(\mathrm{VI})$ was removed. This indicates that inoculation as well as incubation of the RR120 and $\mathrm{Cr}(\mathrm{VI})$ loaded solutions with the strain WS-D/183 might have resulted into their transformation into relatively less toxic products. Our result is in line with previous findings where plants grew better in the azo-dye spiked water after treatment with azo dye decolorizing bacteria (Saratale et al. 2009; Najme et al. 2015; Mahmood et al. 2017). Reduction in phytotoxicity of the decolorized dyes might be attributed to the production of some oxidative enzymes including laccase and tyrosinase during the decolorization process which play their role in degradation of toxic aromatic amines produced during reductive cleavage of azo-dyes into relatively non-toxic/less toxic by-products (Saratale et al. 2009). In order to confirm this hypothesis, there is a need to study the enzymology of the decolorization process by the strain WS-D/183.

\section{Conclusion}

Findings of this study reported that the strain Pseudomonas sp. WS-D/183 can remove dyes and $\mathrm{Cr}(\mathrm{VI})$ simultaneously even in existence of other metal ions, which makes it a valuable biotic source for wastewater treatment. Moreover, the distinctive ability of WS-D/183 for IAA production and $\mathrm{P}$ solubilization suggested its possible use as a bio-inoculant for increased crop production even in metal stressed conditions. However, there is a need to examine the potential of Pseudomonas sp. WS-D/183 for plant growthpromotion in dye contaminated soil using a test crop. Future studies should focused on processes responsible for decolorization of RR120 by the strain WS-D/183 by identifying the genes and enzymes involved in decolorization of azo-dyes using proteomic or metagenomic approaches as well as by characterizing the metabolites using advanced analytical techniques.

\section{Acknowledgement}

This research work was funded by Higher Education Commission (HEC) of Pakistan under funding number 11224436-2PS1-603 and GCUF funded project 85-ENV.SCI-7.

\section{References}

Abbas N, S Hussain, F Azeem, T Shahzad, SH Bhatti, M Imran, Z Ahmad, Z Maqbool, M Abid (2016). Characterization of a salt resistant bacterial strain Proteus sp. NA6 capable of decolorizing reactive dyes in presence of multi-metal stress. World J Microbiol Biotechnol 32:181

Ahemad M, MS Khan (2010). Phosphate-solubilizing plant-growthpromoting Pseudomonas aeruginosa PS1 improves green gram performance in quizalafoppethyl and clodinafop amended soil. Arch Environ Contam Toxicol 58:361-372

Akram MS, M Tariq, M Shahid, M Azeem, MT Javed, S Saleem, S Riaz (2016). Deciphering Staphylococcus sciuri SAT-17 mediated antioxidative defense mechanisms and growth modulations in salt stressed maize (Zea mays L.). Front Microbiol 7:867

Anwar F, S Hussain, S Ramzan, F Hafeez, M Arshad, M Imran, T Yasmeen, N Abbas (2014). Characterization of reactive red-120 decolorizing bacterial strain Acinetobacter junii FA10 capable of simultaneous removal of azo dyes and hexavalent chromium. Water Air Soil Pollut 225:1-16

Arif MS, M Riaz, SM Shahzad, T Yasmeen, A Buttler, JC Garcia-Gil, M Roohi, A. Rasool (2016). Contrasting effects of untreated textile wastewater onto the soil available nitrogen-phosphorus and enzymatic activities in aridisol. Environ Monit Assess 188:1-15

Baig KS, M Arshad, A Khalid, S Hussain, MN Abbas, M Imran (2014). Improving growth and yield of maize through bioinoculants carrying auxin production and phosphate solubilizing activity. Soil Environ 33:159-168

CarneiroPA, GA Umbuzeiro, DP Oliveira, MVB Zanoni (2010). Assessment of water contamination caused by a mutagenic textile effluent/dye house effluent bearing disperse dyes. J Hazard Mater 174:694-699

Chen G, M Huang, L Chen, D Chen (2011). A batch decolorization and kinetic study of Reactive Black 5 by a bacterial strain Enterobacter sp. GY-1. Intl Biodeterior Biodegrad 65:790-796

Desai C, K Jain, B Patel, D Madamwar (2009). Efficacy of bacterial consortium-AIE2 for contemporaneous $\mathrm{Cr}(\mathrm{VI})$ and azo dye bioremediation in batch and continuous bioreactor systems, monitoring steady-state bacterial dynamics using qPCR assays. Biodegradation 20:813-826

Dwivedi S, BR Singh, AA Al-Khedhairy, J Musarrat (2011). Biodegradation of isoproturon using a novel Pseudomonas aeruginosa strain JS-11 as a multi-functional bioinoculant of environmental significance. J Hazard Mater 185:938-944

Gopinath KP, MN Kathiravan, R Srinivasan, S Sankaranarayanan (2011). Evaluation and elimination of inhibitory effects of salts and heavy metal ions on biodegradation of Congo red by Pseudomonas sp. mutant. Bioresour Technol 102:3687-3693

Gordon SA, RP Weber (1951). Colorimetric estimation of indole-acetic acid. Plant Physiol 26:192-195

Hussain S, L Quinn, J Li, E Casey, CD Murphy (2017). Simultaneous removal of malachite green and hexavalent chromium by Cunninghamella elegans biofilm in a semi-continuous system. Intl Biodeterior Biodegrad 125:142-149

Hussain S, Z Maqbool, S Ali, T Yasmeen, M Imran, F Mahmood, F Abbas (2013). Biodecolorization of reactiveblack-5 by a metal and salt tolerant bacterial strain Pseudomonas sp. RA20 isolated from Paharang drain effluents in Pakistan. Ecotoxicol Environ Saf 98:331-338 
Imran M, M Arshad, HN Asghar, M Asghar, DE Crowley (2014). Potential of Shewanella sp. Strain IFN4 to decolorize azo dyes under optimal conditions. Intl J Agric Biol 16:578-584

Imran M, DE Crowley, A Khalid, S Hussain, MW Mumtaz, M Arshad (2015a). Microbial biotechnology for decolorization of textile wastewaters. Rev Environ Sci Biotechnol 14:73-92

Imran M, M Arshad, S Hussain, MW Mumtaz, DE Crowley (2015b). Decolorization of reactive black-5 by Shewanella $\mathrm{sp}$. In the presence of metal ions and salts. Water Environ Res 87:579-586

Imran M, M Arshad, F Negm, A Khalid, B Shaharoona, S Hussain, SM Nadeem, DE Crowley (2016). Yeast extract promotes decolorization of azo dyes by stimulating azoreductase activity in Shewanella sp. strain IFN4. Ecotoxicol Environ Saf 124:42-49

Imtiazuddin SM, M Mumtaz, T Ahmed (2014). Physico-chemical analysis and heavy metals concentration in textile effluent in Karachi region of Pakistan. Global J Environ Sci Technol 2:71-74

Johansson HE, MK Johansson, AC Wong, ES Armstrong, EJ Peterson, RE Grant, MA Roy, MV Reddington, RM Cook (2011). BTI1, an azoreductase with pH-dependent substrate specificity. Appl Environ Microbiol 77:4223-4225

Mahmood F, M Shahid, S Hussain, T Shahzad, M Tahir, M Ijaz, A Hussain, K Mahmood, M Imran, SAK Babar (2017). Potential plant growthpromoting strain Bacillus sp. SR-2-1/1 decolorized azo dyes through NADH-ubiquinone:oxidoreductase activity. Bioresour Technol 235:176-184

Mahmood S, A Khalid, T Mahmood, M Arshad, R Ahmad (2013). Potential of newly isolated bacterial strains for simultaneous removal of hexavalent chromium and reactive black-5 azo dye from tannery effluent. J Chem Technol Biotechnol 88:1505-1513

Maliha R, K Samina, A Najma, A Sadia, L Farooq (2004). Organic acids production and phosphate solubilization by phosphate solubilizing microorganisms under in vitro conditions. Pak J Biol Sci 7:187-196

Maqbool Z, HN Asghar, S Hussain, M Riaz, S Ali, MS Arif, M Maqsood (2015). Isolating, screening and applying chromium reducing bacteria to promote growth and yield of okra (Hibiscus esculentus L.) in chromium contaminated soils. Ecotoxicol Environ Saf 114:343-349

Maqbool Z, S Hussain, T Ahmad, H Nadeem, M Imran, A Khalid, M Abid, F Martin-Laurent (2016). Use of RSM modeling for optimizing decolorization of simulated textile wastewater by Pseudomonas aeruginosa strain ZM130 capable of simultaneous removal of reactive dyes and hexavalent chromium. Environ Sci Pollut Res 23:11224-11239

Maqbool Z, S Hussain, F Mahmood, M Shahid, T Shahzad, T Ahmed, A Sahar, M Imran, Z Ahmad, F Hafeez (2018). Metal-Tolerant Pseudomonas aeruginosa Strain ZM130 has the potential for concurrent dye decolorization and plant growth promotion. Intl $J$ Agric Biol 20:2621-2631
Moutaouakkil A, Y Zeroual, FZ Dzayri, M Talbi, K Lee, M Blaghen (2003). Purification and partial characterization of azoreductase from Enterobacter agglomerans. Arch Biochem Biophys 413:139-146

Najme R, S Hussain, Z Maqbool, M Imran, F Mahmood, H Manzoor, T Yasmeen, T Shehzad (2015). Biodecolorization of Reactive Yellow2 by Serratia sp. RN34 isolated from textile wastewater. Water Environ Res 87:2065-2075

Ong SA, E Toorisaka, M Hirata, T Hano (2012). Decolorization of Orange II using an anaerobic sequencing batch reactor with and without cosubstrates. J Environ Sci 24:291-296

Oyetibu GO, MO Ilori, OS Obayori, OO Amund (2013). Chromium (VI) biosorption properties of multiple resistant bacteria isolated from industrial sewage. Environ Monit Assess 185:6809-6818

Park D, YS Yun, JM Park (2006). Comment on the removal mechanism of hexavalent chromium by biomaterials or biomaterial based activated carbons. Ind Eng Chem Res 45:2405-2407

Perriere C, M Gouy (1996). WWW-Query: an on-line retrieval system for biological sequence banks. Biochemistry 78:1288-1296

Pratum C, J Wongthanate, C Arunlertaree, B Prapagdee (2011). Decolorization of reactive dyes and textile dyeing effluent by Pleurotus sajorcajo. Intl J Integr Biol 11:52-57

Quintelas C, B Fernandes, J Castro, H Figueiredo, T Tavares (2008). Biosorption of $\mathrm{Cr}(\mathrm{VI})$ by a Bacillus coagulans biofilm supported on granular activated carbon (GAC). Chem Eng J 136:195-203

Rehman K, T Shahzad, A Sahar, S Hussain, F Mahmood, MH Siddique MA Siddique, MI Rashid (2018). Effect of Reactive Black 5 azo dye on soil processes related to $\mathrm{C}$ and $\mathrm{N}$ cycling. Peer J 6:e4802

Saratale RG, GD Saratale, JS Chang, SP Govindwar (2009). Decolorization and biodegradation of textile dye Navy blue HER by Trichosporon beigelii NCIM-3326. J Hazard Mater 166:1421-1428

Shah MP, KA Patel, SS Nair, AM Darji (2014). Microbial degradation and decolorization of reactive dyes by Bacillus Spp. ETL-1979. Amer J Microbiol Res 2:16-23

Shahid M, S Hameed, M Tariq, M Zafar, A Ali, N Ahmad (2015). Characterization of mineral phosphate-solubilizing bacteria for enhanced sunflower growth and yield-attributing traits. Ann Microbiol 65:1525-1536

Tony BD, D Goyal, S Khanna (2009). Decolorization of Direct Red 28 by mixed bacterial culture in an up-flow immobilized bioreactor. $J$ Ind Microbiol Biotechnol 36:955-960

Tuzen M, A Onal, M Soylak (2008). Determination of trace heavy metals in some textile products produced in Turkey. Bull Chem Soc Ethiop 22:379-384

Wani R, KM Kodam, KR Gawai, PK Dhakephalkar (2007). Chromate reduction by Burkholderia cepacia MCMB-821, isolated from the pristine habitat of alkaline Crater Lake. Appl Microbiol Biotechnol 75:627-632 